\title{
Association of Clinical Evaluation and Patient's Level of Satisfaction among Complete Denture Wearer
}

\author{
Putri Welda Utami Ritonga \\ Department of Prosthodontics \\ Faculty of Dentistry, Universitas Sumatera Utara \\ Medan, Indonesia \\ welldone_puti@yahoo.com
}

\author{
Luveena Loshini Prabakaran \\ Faculty of Dentistry, Universitas Sumatera Utara \\ Medan, Indonesia \\ luveena07@gmail.com
}

\begin{abstract}
Dentist's evaluation of complete denture differs from patient's evaluation. Dentists prioritize the clinical aspects of dentures, such as vertical dimension, aesthetic, stability and denture-bearing area while patients measures their satisfaction based on aspects, like aesthetic, mastication, comfort and phonetic. The aim of the present study was to investigate the relationship of clinical evaluation and patient's level of satisfaction among complete denture wearers. This was a descriptive-analytic study with cross-sectional design. The sampling method used was purposive sampling, with subjects of 30 people. All subjects were interviewed using a questionnaire prior to clinical evaluation conducted on them. Data were then analyzed with Fisher test and result showed significant association of clinical evaluation and patient's level of satisfaction in vertical dimension and phonetics $(p=$ $\mathbf{0 , 0 0 6 )}$, whereas no association of aesthetic (clinical evaluation) and aesthetic (patient's satisfaction) were found $(p=0,267)$. It can be concluded from the different results of the clinical evaluation and patient's level of satisfaction that patients gave lower or higher score compared to the score given by the dentist. Therefore, the success of complete denture treatment cannot be determined solely on the patient's satisfaction level, but the clinical evaluation need to be taken into consideration to increase the success rate of the treatment.
\end{abstract}

Keywords-complete dentures, evaluation, satisfaction

\section{INTRODUCTION}

Complete tooth loss is a condition where an individual experiences complete loss of tooth commonly due to caries, periodontal diseases, or trauma [1]. Complete denture (CD) is the ultimate treatment for complete tooth loss mainly due to its relatively cheap cost compared to implant-retained overdentures.

Majority of patients are satisfied with their CDs. However, some patients, approximately $10-15 \%$, remain dissatisfied, even if the dentures are constructed according to all accepted criteria [2]. Post-treatment evaluation is important to determine the cause of dissatisfaction and to increase patient's satisfaction level in CD treatment. Post-treatment evaluation can be classified into two; patient's evaluation and dentist's evaluation. Patient's evaluation on CD treatment is based on satisfaction level in phonetic, mastication, aesthetic, and comfort. Dentist's evaluation on CD treatment is based on clinical evaluation of vertical dimension, aesthetic, stability, and denture-bearing area. Dentists prioritize the quality of dentures while patients prioritize comfort, functional, and aesthetic of dentures.

The studies by Vanaken (1989) and AJ Marinus (1990) showed positive correlation between patient's level of satisfaction and technical aspects of CD but Carlson (1867), Langer (1962), and Kalk (1979) found no correlation [3]. Dentists commonly use vertical dimension for post-treatment evaluation of $\mathrm{CD}$. Carlsson and Persson (2001) found that $26.3 \%$ of CD wearers had high vertical dimension while $71.7 \%$ of CD wearers had low vertical dimension [4]. An extremely low vertical dimension will result in the production of lisping sound when ' $s$ ' is pronounced, while extremely high vertical dimension will result in clicking sound when both the upper and lower CDs come to contact. In addition, aesthetic is also a crucial factor that determines the success of CD treatment. Patient's and dentist's perception of aesthetic often varies. Patients also have high expectations of their dentures in terms of aesthetic and also expects their denture to look like the natural dentitions [5].

\section{MATERIALS AND METHODS}

This study was a descriptive-analytic with a cross sectional approach. The sampling method used was a non probability method (purposive sampling0. The population of the study was patients wearing CD made by co-assistants in the Prosthodontics Clinic of Faculty of Dentistry, University of North Sumatra, Medan from January 2013 - June 2015. The number of sample in this study was in accordance with the minimum requirement proposed by Bailey and Gay that is 30 peoples. All subjects were interviewed using a questionnaire, prior to clinical evaluation of their $\mathrm{CD}$ using a evaluation form. Clinical evaluation includes the evaluation of vertical dimension and aesthetics of CDs. Patients were instructed to occlude the upper and lower jaw, then the occlusion line of patients was recorded. Patients were then instructed to pronounce the 
word 'yes' and the closest speaking space were recorded. The difference between both the lines were later recorded.

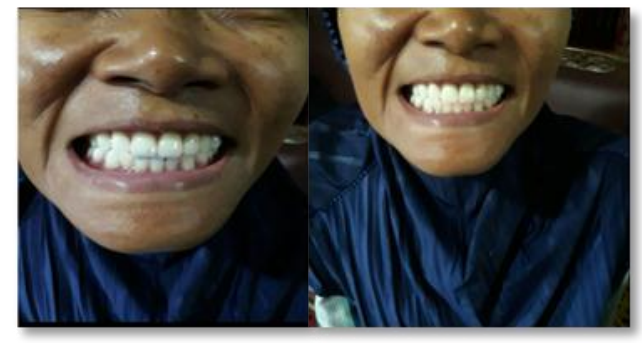

A

Figure 1. Evaluation of vertical dimension. A. Occlusal line. B. Closet speaking space.

Aesthetic of dentures were evaluated visually based on upper lip support, smile line, occlusal plane, and gingival contour. Fisher test was used to analyze the relationship between the clinical evaluation and CD wearing patient's level of satisfaction as data were not distributed normally.

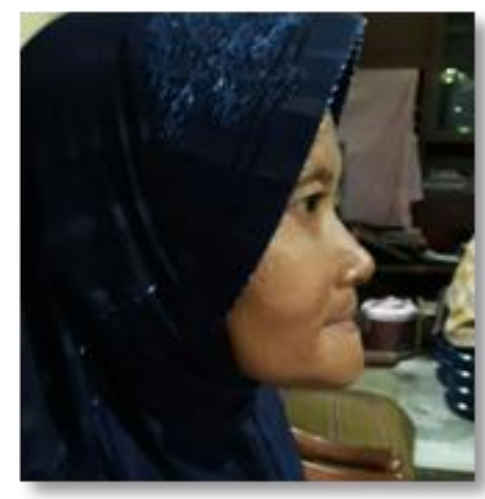

Figure 2. Evaluation of lip support.

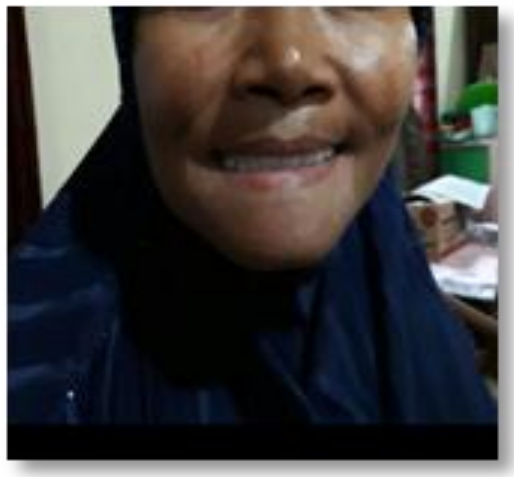

Figure 3. Evaluation of smile line.

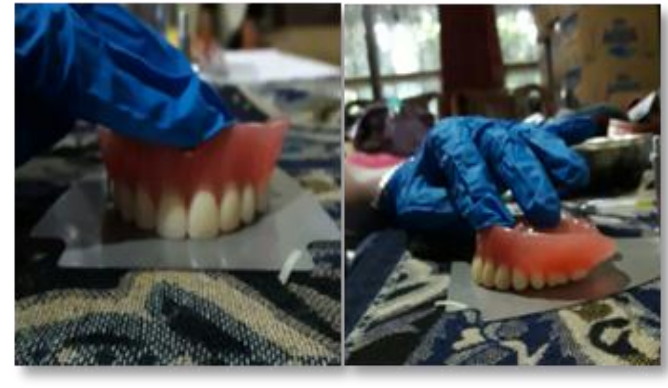

Figure 4. Evaluating occlusal plane. A. Frontal view. B. Lateral view.

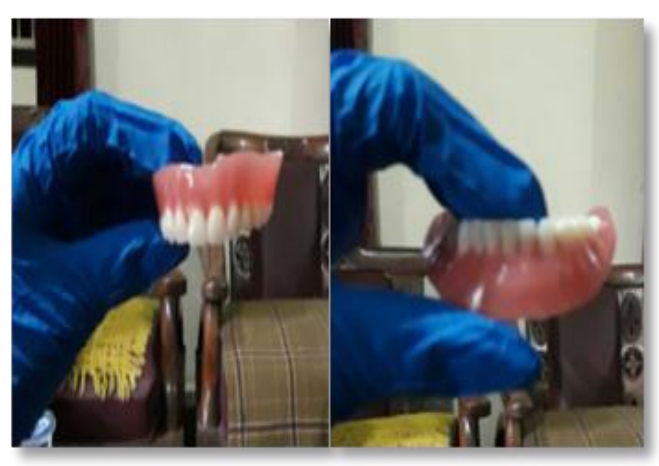

A

B

Figure 5. Evaluating contour of gingival. A. Upper jaw. B. Lower jaw.

\section{RESULTS}

A. Distribution of clinical evaluation among sample

Vertical dimension of CDs were mostly scored as 5 (very good), with the percentage of $40 \%$. Aesthetic of CDs were mostly scored as 4 (good), with the percentage of $43.3 \%$ (Table I). TABLE I. DISTRIBUTION OF CLINICAL EVALUATION
AMONG SAMPLE

\begin{tabular}{|l|l|l|}
\hline \multicolumn{1}{|c|}{ Clinical Evaluation } & \multicolumn{1}{c|}{ n } & \% \\
\hline \multicolumn{3}{|c|}{ 1. } \\
\hline Score 1 & 1 & 3.3 \\
\hline Score 2 Dimension & 13.3 \\
\hline Score 3 & 4 & 16.7 \\
\hline Score 4 & 5 & 26.7 \\
\hline Score 5 & 8 & 40 \\
\hline Total & 12 & 100 \\
\hline \multicolumn{2}{|l}{} \\
\hline Score 1 & 30 & 0 \\
\hline Score 2 & 0 & 3.3 \\
\hline Score 3 & 1 & 26.7 \\
\hline Score 4 & 8 & 43.3 \\
\hline Score 5 & 13 & 26.7 \\
\hline Total & 8 & 100 \\
\hline
\end{tabular}

B. Distribution of patient's level of satisfaction among sample

Patient's satisfaction in phonetic were mostly scored as 4 (satisfied) and 5 (extremely satisfied), with the percentage of $33.3 \%$. Patient's satisfaction in aesthetic were mostly scored as 4 (satisfied), with the percentage of $50 \%$ (Table II). 
TABLE II. DISTRIBUTION OF PATIENT'S LEVEL OF SATISFACTION AMONG SAMPLE

\begin{tabular}{|c|c|c|}
\hline Patient's Satisfaction Level & $\mathbf{n}$ & $\%$ \\
\hline \multicolumn{3}{|c|}{ 1. Phonetic } \\
\hline Score 1 & 1 & 3.3 \\
\hline Score 2 & 3 & 10 \\
\hline Score 3 & 6 & 20 \\
\hline Score 4 & 10 & 33.3 \\
\hline Score 5 & 10 & 33.3 \\
\hline Total & 30 & 100 \\
\hline \multicolumn{3}{|c|}{ 2. Aesthetic } \\
\hline Score 1 & 0 & 0 \\
\hline Score 2 & 1 & 3.3 \\
\hline Score 3 & 0 & 0 \\
\hline Score 4 & 15 & 50.0 \\
\hline Score 5 & 14 & 46.7 \\
\hline Total & 30 & 100 \\
\hline
\end{tabular}

C. Distribution of clinical evaluation and patient's satisfaction level among sample

Majority patients were extremely satisfied with their CDs in terms of phonetic, which were the ones with vertical dimension that were evaluated as very good in clinical evaluation, with the percentage of $26.7 \%$. Majority patients were extremely satisfied with their CDs in terms of aesthetics, however, the CDs in terms of aesthetics were clinically evaluated as only good, with the proportion of $26.7 \%$ (Table III).

TABLE III. DISTRIBUTION OF CLINICAL EVALUATION AND PATIENT'S LEVEL OF SATISFACTION AMONG SAMPLE

\begin{tabular}{|c|c|c|c|c|c|c|c|c|c|c|c|}
\hline \multirow{4}{*}{$\begin{array}{c}\begin{array}{c}\text { Clinical } \\
\text { Eva- } \\
\text { luation } \\
\text { (Score) }\end{array} \\
1 . \mathrm{VD}\end{array}$} & \multirow{2}{*}{\multicolumn{10}{|c|}{$\begin{array}{c}\text { Patients Satisfaction Level } \\
\text { Phonetic }\end{array}$}} & \multirow{4}{*}{ Total } \\
\hline & & & & & & & & & & & \\
\hline & \multicolumn{2}{|c|}{ Score 1} & \multicolumn{2}{|c|}{ Score 2} & \multicolumn{2}{|c|}{ Score 3} & \multicolumn{2}{|c|}{ Score 4} & \multicolumn{2}{|c|}{ Score 5} & \\
\hline & $\mathrm{n}$ & $\%$ & $\mathrm{n}$ & $\%$ & $\mathrm{n}$ & $\%$ & $\mathrm{n}$ & $\%$ & $\mathrm{n}$ & $\%$ & \\
\hline 1 & 0 & 0 & 1 & 3.3 & 0 & 0 & 0 & 0 & 0 & 0 & 1 \\
\hline 2 & 1 & 3.3 & 1 & 3.3 & 1 & 3.3 & 0 & 0 & 1 & 3.3 & 4 \\
\hline 3 & 0 & 0 & 0 & 0 & 2 & 6.7 & 3 & 10 & 0 & 0 & 5 \\
\hline 4 & 0 & 0 & 1 & 3.3 & 1 & 3.3 & 5 & 16.7 & 1 & 3.3 & 8 \\
\hline 5 & 0 & 0 & 0 & 0 & 2 & 6.7 & 2 & 6.7 & 8 & 26.7 & 12 \\
\hline Total & 1 & 3.3 & 3 & 10 & 6 & 20 & 10 & 33.3 & 10 & 33.3 & 30 \\
\hline \multicolumn{12}{|c|}{ Aesthetic } \\
\hline $\begin{array}{l}\text { 2. Esthe- } \\
\text { tic }\end{array}$ & $\mathrm{n}$ & $\%$ & $\mathrm{n}$ & $\%$ & $\mathrm{n}$ & $\%$ & $\mathrm{n}$ & $\%$ & $\mathrm{n}$ & $\%$ & \\
\hline 1 & 0 & 0 & 0 & 0 & 0 & 0 & 0 & 0 & 0 & 0 & 0 \\
\hline 2 & 0 & 0 & 0 & 0 & 0 & 0 & 1 & 3.3 & 0 & 0 & 1 \\
\hline 3 & 0 & 0 & 1 & 3.3 & 0 & 0 & 3 & 10 & 4 & 13.3 & 8 \\
\hline 4 & 0 & 0 & 0 & 0 & 0 & 0 & 5 & 16.7 & 8 & 26.7 & 13 \\
\hline 5 & 0 & 0 & 0 & 0 & 0 & 0 & 6 & 20 & 2 & 6.7 & 8 \\
\hline Total & 0 & 0 & 1 & 3.3 & 0 & 0 & 15 & 50 & 14 & 46.7 & 30 \\
\hline
\end{tabular}

D. Relationship between clinical evaluation and patient's level of satisfaction among sample

Fisher's test shows a significant relationship between vertical dimension and phonetics $(p=0,0006)$, while no relationship were found between aesthetic (clinical evaluation) and aesthetic (patient's satisfaction) $(\mathrm{p}=0,267)$ (Table IV).

TABLE IV. RELATIONSHIP BETWEEN CLINICAL EVALUATION AND PATIENT'S LEVEL OF SATISFACTION AMONG SAMPLE

\begin{tabular}{|l|l|c|}
\hline \multicolumn{1}{|c|}{ Clinical Evaluation } & Patient's Satisfaction Level & p \\
\hline Vertical Dimension & Phonetic & $0,006^{*}$ \\
\hline Aesthetics & Aesthetics & 0,267 \\
\hline
\end{tabular}

\section{DISCUSSION}

This study shows that most vertical dimension of the CDs was evaluated as very good. This might be due to short-period use of dentures, which were 1-2 years. Therefore, the wear and tear of the tooth has not occurred. Aesthetic of CDs were mostly evaluated as good. The evaluation of CDs, in terms of aesthetic, is more subjective, resulting in different result compared to the study of Celebic A, in which aesthetic of CDs were mostly evaluated as very good [2].

This study also shows that most patients were satisfied and very satisfied with their CDs in terms of phonetic. This might be due to the usage of dentures which enables patients to pronounce well and speak better, causing patient to feel satisfied and very satisfied with their CDs in terms of phonetic. Most patients were only satisfied with their CDs in terms of aesthetics as it is largely influenced by psychological factor. Patients, who are anxious, timid and nervous, are more likely to face difficulties in accepting their dentures [6].

This study shows a similarity between the phonetic scores and vertical dimension scores among most patients. However, there is a difference between the scores among a small group of patients. The difference is probably because patients who wear CDs are usually elderly people, who are most likely to have lower tolerance towards change that leads to difficulties to adapt to their CDs. Hence, they expressed average satisfaction towards their CDs in terms of phonetic, despite the vertical dimension of $\mathrm{CDs}$ that was evaluated as very good. This study also shows that most patients gave lower or higher score than the score given in clinical evaluation in terms of aesthetics. The difference might be due to subjective evaluation of aesthetics, in which every patient's perception of aesthetic differs due to the influence of culture and personal identity [7].

This study also shows a significant relationship between vertical dimension and patient's level of satisfaction in terms of phonetic. The better the vertical dimension of CDs, the better the patient's satisfaction level in terms of phonetic. This study also shows no relationship between aesthetics (clinical evaluation) and aesthetic (patient's satisfaction level).

As a whole, the success of CD treatment cannot be determined solely on patient's satisfaction level, which is influenced by many subjective factors such as personality, psychological factors, previous denture experience, expectations before denture fabrications, and oral conditions. Therefore, clinical evaluation of CDs needs to be taken into serious consideration to increase the success rate of CD treatment.

\section{REFERENCES}

[1] K. Peltzer, S. Hewlett, A.E. Yawson, "Prevalence of Loss of All Teeth (Edentulism) and Associated Factors in Older Adults in China, Ghana, India, Mexico, Russia and South Africa," Int. J. Environ. Res. Public Health, vol. 11, pp. 11308-11324, 2014.

[2] A. Celebic, "The Patient's and the Therapist's Evaluation of Complete Denture Therapy," Coll. Antropol, vol. 24, pp. 71-77, 2000.

[3] A.A. Shah, "Quality of dentures and patient satisfaction," PJMHS, vol. 3, pp. 140-142, 2009. 
[4] H. Hadjieva, "Changes in the vertical dimension of occlusion during different periods of complete denture wear - a comparative study," I J of IMAB, vol. 20, pp. 546-549, 2014.

[5] M.R. Memon, F. Ghani, M. Shahzad, "Functional assessment of removable complete dentures, " Pakistan Oral \& Dental Journal, vol. 33, pp. 563-565, 2013.

[6] S. Faruqui, S.M. Haider, N. Ahmed, "Esthetic and function evaluation after treatment with removable dentures by patients, lay persons, dentists in a dental school of Pakistan," Pakistan Oral \& Dental Journal, vol. 35, pp.730-734, 2015.

[7] R.T. Basting, R.S. Trindade, F.M. Florio, "Comparative study of smile analysis by subjective and computerized methods," Operative Dentistry, vol. 319, pp. 652-659, 2006. 